\title{
IN VITRO ALPHA AMYLASE INHIBITORY ACTIVITY OF CRUDE ETHANOL EXTRACT OF TERMINALIA CHEBULA LEAVES
}

\section{Uma Sankar Gorla*, M. Savithri, P Sravani, P. Prudhviraj, M. Srimulya and GSN Koteswara Rao}

Viswanadha Institute of Pharmaceutical Sciences, Visakhapatnam, Andhra Pradesh, India.

*Corresponding author e-mail: umasankargorla@gmail.com

\begin{abstract}
:
The present study was aimed to decrease post-prandial hyperglycemic levels in diabetic patients by inhibiting the enzyme alpha amylase using ethanol extract of Terminalia chebula leaves. Terminalia chebula leaves were subjected to soxhlet extraction using ethanol and studied wheat alpha amylase and alpha amylase inhibitory activity according to standard method. The results showed that ethanol leaf extract exhibit appreciable inhibition activity by dose dependent manner and the results were statistically significant with $\mathrm{p}<0.001$ by using two way ANOVA followed by Bonferroni post test. Terminalia chebula may essentially contain herbal bioactive compounds that can mitigate post-prandial hyperglycemia and further structural elucidation and characterization methodologies have to be carried out in order to identify the bioactive constituents.
\end{abstract}

Key words: Terminalia chebula; wheat alpha amylase; alpha amylase; hyperglycemia; diabetes mellitus; soxhlet extractor.

\section{INTRODUCTION:}

Diabetes mellitus is a complex endocrine metabolic disorder that results in increased blood glucose levels due to absolute or relative deficiency of insulin. ${ }^{[1]}$ It is one of the five leading causes of death worldwide, nearly 300 million Indians are expected to be diabetic by the year 2025.2] Post-prandial serum hyperglycemic levels can be decreased through the inhibition of carbohydrate hydrolyzing enzyme like alpha amylase, which acts as target therapeutic advance for treating type II diabetes.[3] Inhibitors of pancreatic alpha amylase delay carbohydrate digestion causing a reduction in the rate of glucose absorption and lowering the postprandial serum glucose levels. ${ }^{[4]}$ Synthetic alpha amylase inhibitors currently in clinical use are acarbose and miglitol. Their limitations include non-specificity, produce serious side effects such as bloating, abdominal discomfort, diarrhea and flatulence and failure to elevate diabetic complications.[5] Therefore, screening of alpha amylase inhibitors in medicinal plants has received immense attention.

For a long time natural products have been used for the treatment of diabetes, mainly in developing countries where the resources are limited and affordability and access to modern treatment is a problem.[6] Terminalia chebula also called as Black myrobalan, a traditional medicine extensively used in unani, ayurveda and homeopathic medicine. The biologically active chemicals of Terminalia chebula shows a wide spectrum of pharmacological activities and has been reported as antioxidant,[7] antidiabetic,[8] antibacterial,[9] antiviral[10] etc. The present study was carried out to investigate the alpha 
amylase inhibitory activity of crude ethanol extract of Terminalia chebula leaves.

\section{MATERIALS AND METHODS}

\section{Collection of plant material}

The fresh leaves of Terminalia chebula were collected from the herbal garden of Viswanadha Institute of Pharmaceutical Sciences, Visakhapatnam. The leaves were dried in shade for about a month, powdered, sieved and stored in air tight container for further studies.

\section{Preparation of plant extract}

The powdered and sieved leaf material of Terminalia chebula was extracted by using soxhlet apparatus.[11] $50 \mathrm{gm}$ of dried powdered leaf material was packed in the soxhlet column and extracted for 10-12 hours using ethanol as solvent. Then the extracted fluid was concentrated by using distillation apparatus for a period of 2-3 hours and then air dried over night at room temperature and the percentage yield was calculated.

\section{Extraction of wheat alpha amylase}

$500 \mathrm{gm}$ of malted whole wheat flour was added slowly to 1 litre of $0.2 \%$ calcium acetate with continuous stirring for about 2 hours at room temperature. The suspension was cooled to $4^{\circ} \mathrm{C}$ and then centrifuged at $7500 \mathrm{rpm}$ for 10 minutes. The clear brown supernatant was subjected to heat treatment at $70^{\circ} \mathrm{C}$ for 15 minutes in order to inactivate beta amylase because it may interferes with the enzymatic determination of alpha amylase. Alpha amylase was resistant to heat treatment and the $\mathrm{pH}$ was adjusted to 6.6 with $4 \%$ cold ammonium hydroxide. Heat treatment was carried out at 85 to $90^{\circ} \mathrm{C}$ with continuous stirring and then cooled to $2-3^{\circ} \mathrm{C}$ until use. ${ }^{[12]}$

\section{In vitro wheat alpha amylase and alpha amylase inhibition assay}

The wheat alpha amylase and alpha amylase inhibitory effect of ethanolic leaf extract of Terminalia chebula was determined according to standard method.[13] For wheat alpha amylase inhibition assay, the mixture containing $200 \mu \mathrm{l}$ of $0.02 \mathrm{M}$ sodium phosphate buffer, $200 \mu \mathrm{l}$ of wheat alpha amylase extract and $100 \mu \mathrm{l}$ of different concentrations of ethanol extract of Terminalia chebula leaves were incubated for 10 minutes at room temperature and added $200 \mu \mathrm{l}$ of $1 \%$ starch solution in all incubated test tubes. Then added $500 \mu \mathrm{l}$ of dinitrosalicylic acid areagent and placed in boiling water bath for 5 minutes, cooled and diluted with $15 \mathrm{ml}$ of distilled water and absorbance was measured at $540 \mathrm{~nm}$. The control was prepared without any plant extracts. Acarbose was used as the reference standard. The percentage inhibition was calculated using the formula.

$$
\% \text { Inhibition }=\frac{\mathrm{A} 540 \text { control }-\mathrm{A} 540 \text { extract }}{\text { A540 control }} \times 100
$$

Where, $\mathrm{A} 540=$ Absorbance at $540 \mathrm{~nm}$.

The alpha amylase inhibition activity of the plant was assayed by the same method used for wheat alpha amylase inhibition activity.

\section{Statistical analysis}

Results were expressed as mean \pm standard error of mean (SEM), $(n=3)$. Statistical analysis was carried out using two way ANOVA followed by Bonferroni post test in Graph Pad Prism 5 software. P values $<0.001$ were considered significant.

\section{RESULTS AND DISCUSSION}

The dried powdered leaves of Terminalia chebula were extracted with ethanol, percentage yield calculated was $23.08 \%$ and assayed for in vitro wheat alpha amylase and 
alpha amylase inhibitory activity. The assay was carried out using five different concentrations $(20,40,60,80$ and 100 $\mu \mathrm{g} / \mathrm{ml}$ ), the extract showed significant alpha amylase and wheat alpha amylase inhibitory activity at all the tested concentrations and the results have been tabulated in table 1 and 2 respectively. The results indicated that the ethanolic leaf extract exhibited appreciable inhibition activity against wheat alpha amylase and alpha amylase in comparison with acarbose. There was a dose dependent increase in percent inhibition against wheat alpha amylase and alpha amylase by ethanol extract of Terminalia chebula (figure $1 \& 2$ ). The present study indicated that Terminalia chebula could be useful in management of post-prandial hyperglycemia.

Table 1: Percentage inhibition of wheat alpha amylase

\begin{tabular}{ccc}
\hline $\begin{array}{c}\text { Concentration } \\
(\boldsymbol{\mu g} / \mathbf{m l})\end{array}$ & $\begin{array}{c}\text { Acarbose } \\
\text { (Standard) }\end{array}$ & $\begin{array}{c}\text { Terminalia chebula } \\
\text { (Ethanol extract) }\end{array}$ \\
\hline 100 & $90.53 \pm 0.67$ & $45.14 \pm 0.85$ \\
80 & $81.63 \pm 0.85$ & $32.67 \pm 0.49$ \\
60 & $63.17 \pm 0.87$ & $22.55 \pm 0.89$ \\
40 & $55.21 \pm 1.32$ & $10.41 \pm 0.49$ \\
20 & $41.08 \pm 1.03$ & $6.53 \pm 0.33$ \\
\hline
\end{tabular}

NOTE: All values are represented as mean \pm SEM $(n=3)$. All results were statistically significant with $\mathrm{p}<0.001$ compared with standard drug.

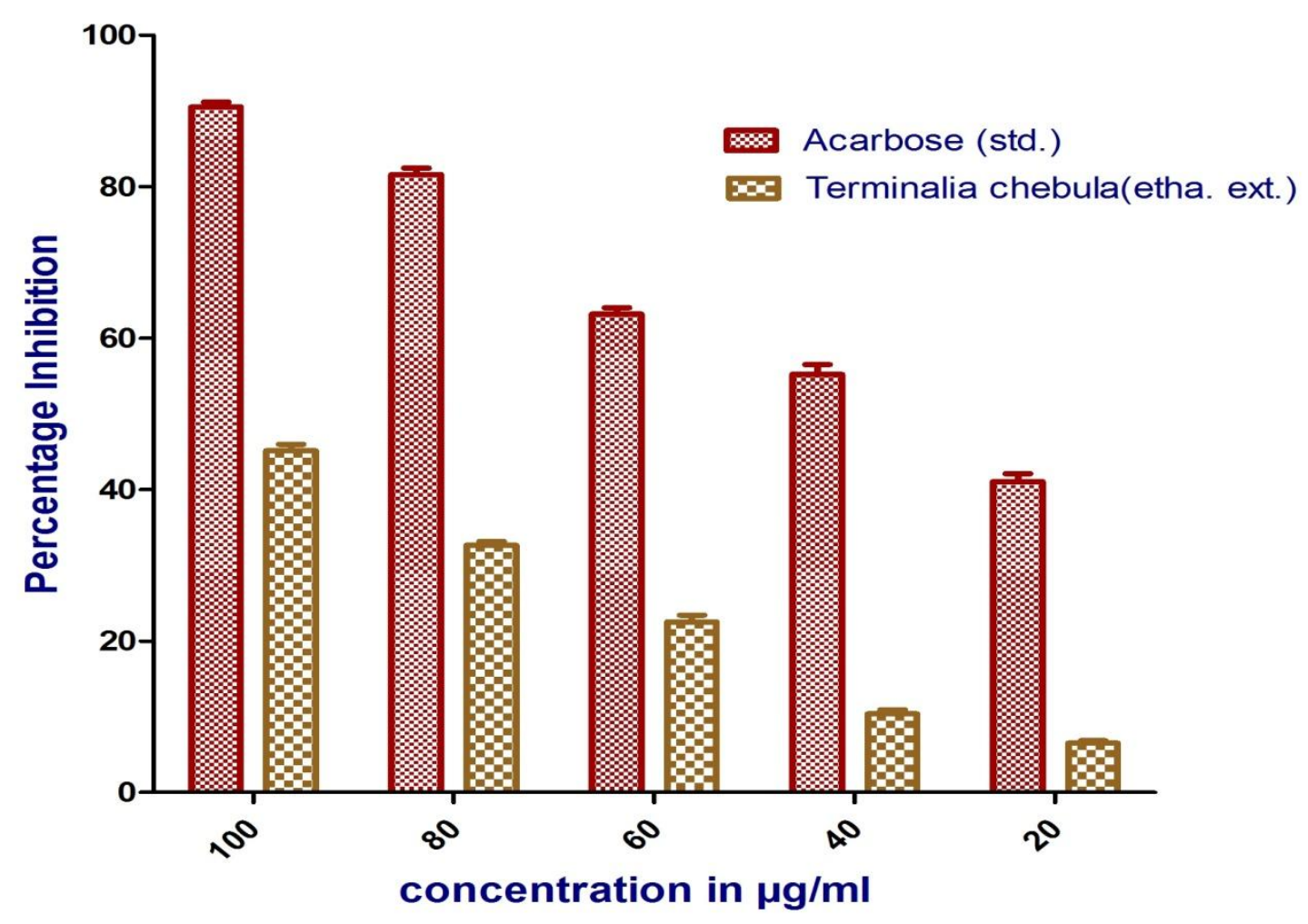

Fig.1: Percentage inhibition of wheat alpha amylase 
Table 2: Percentage inhibition of alpha amylase

\begin{tabular}{ccc}
\hline $\begin{array}{c}\text { Concentration } \\
(\boldsymbol{\mu g} / \mathbf{m l})\end{array}$ & $\begin{array}{c}\text { Acarbose } \\
\text { (Standard) }\end{array}$ & $\begin{array}{c}\text { Terminalia chebula } \\
\text { (Ethanol extract) }\end{array}$ \\
\hline 100 & $89.33 \pm 1.10$ & $50.85 \pm 0.96$ \\
80 & $77.43 \pm 0.85$ & $38.31 \pm 0.87$ \\
60 & $63.85 \pm 0.78$ & $27.20 \pm 0.69$ \\
40 & $53.60 \pm 0.84$ & $21.21 \pm 1.22$ \\
20 & $42.52 \pm 0.70$ & $11.02 \pm 0.23$ \\
\hline
\end{tabular}

NOTE: All values are represented as mean \pm SEM $(n=3)$. All results were statistically significant with $\mathrm{p}<0.001$ compared with standard drug.

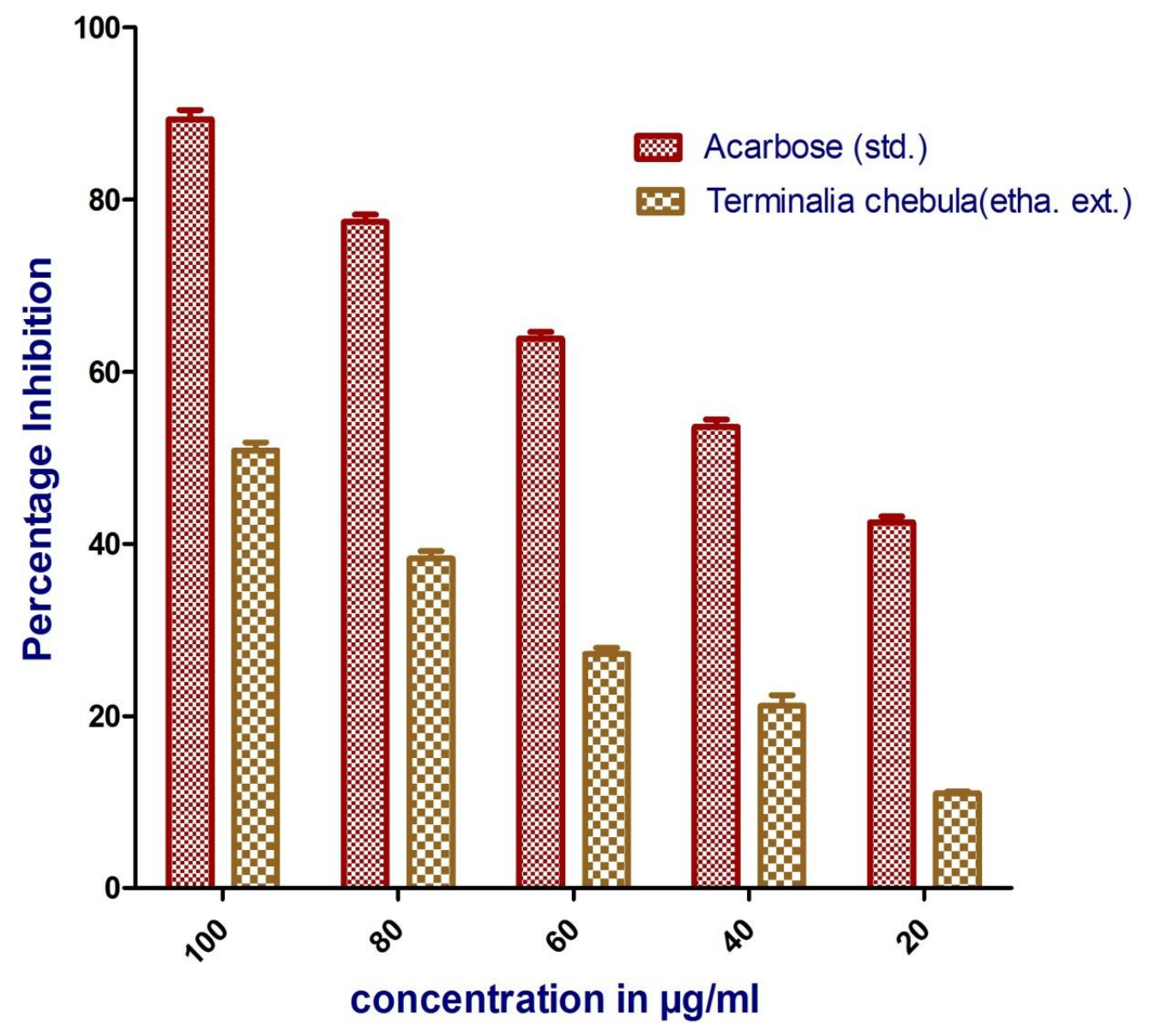

Fig. 2: Percentage inhibition of alpha amylase

\section{CONCLUSION}

The results of the present study indicated that the ethanolic leaf extract of Terminali chebula showed the appreciable wheat alpha amylase and alpha amylase inhibitory activity www.ijapbjournal.com compared to the standard and can mitigate post-prandial hyperglycemia. Terminalia chebula may essentially contain herbal bioactive compounds inhibiting enzyme activity and further structural elucidation and 
characterization methodologies have to be carried out in order to identify the bioactive constituents. Based on the present investigation, it can be concluded that the selected plant leaves are containing chemical constituents that shows promising treatment for post-prandial hyperglycemia.

\section{ACKNOWLEDGEMENT}

The authors are thankful to the management, principal and staff of Viswanadha Institute of Pharmaceutical Sciences for their support in conducting the present investigation.

\section{REFERENCES}

1. American Diabetes Association. Standards of medical care in diabetes, Diabetes care, 2008; 31(1): S12-S54.

2. OP Gupta and Sanjeev Phatak. Pandemic trends in prevalence of diabetes mellitus and associated coronary heart disease in India - Their causes and prevention. Int. J. Diab. Dev. Countries, 2003; 23: 37-49.

3. Sindhu.S. Nair, Vaibhavi Kavrekar and Anshu Mishra. In vitro studies on alpha amylase and alpha glucosidase inhibitory acitivities of selected plant extracts. Euro. J. Exp. Bio., 2013; 3(1): 128-132.

4. Tarling CA, Woods $\mathrm{K}$, Zhang R, Brastianos HC, Brayer GD, Andersen RJ, Withers SG. The search for novel human pancreatic $\alpha$ amylase inhibitors: high-throughput screening of terrestrial and marine natural product extracts. Chem. BioChem., 2008; 9(3): 433-438.

5. Alice Y.Y. Cheng and I. George Fantus. Oral antihyperglycemic therapy for type 2 diabetes mellitus. Can. Med. Assoc. J., 2005; 172(2): 213-226.
6. Bahman Nickavar and Nasibeh Yousefian. Inhibitory effects of six Allium species on $\alpha$-amylase enzyme activity. Iran J. Pharm. Res., 2009; 8(1): 53-57.

7. Subramaniyan Suchalatha, Chennam Srinivasulu and Shyamala Devi. Antioxidant activity of ethanolic extract of Terminalia chebula fruit against isoproterenol-induced oxidative stress in rats. Ind. J. of Biochem. Biophys., 2005; 42: 246-249.

8. Rao NK and Nammi S. Antidiabetic and renoprotective effects of the chloroform extract of Terminalia chebula Retz. seeds in streptozotocin -induced diabetic rats. BMC Complement Altern. Med., 2006; 6: 17.

9. Kannan P, Ramadevi SR and Waheeta Hooper. Antibacterial activity of Terminalia chebula fruit extract. Afr. J. Microbiol. Res., 2009; 3(4): 180-184.

10. Kim TG, Kang SY, Jung KK, Kang JH, Lee E, Han HM and Kim SH. Antiviral activities of extracts isolated from Terminalia chebula Retz., Sanguisorba officinalis L., Rubus coreanus Miq and Rheum palmatum L. against hepatitis B virus. Phytother. Res., 2001; 15(8): 718-720.

11. William B. Jensen. The origin of the soxhlet extractor. J. Chem. Educ., 2007; 84(12):.1913.

12. Kneen E, Sandstedt RM and Hollenbeck CM. The differential stability of the malt amylases -separation of the alpha and beta components. Cereal Chem., 1943; 20: 399-423.

\section{How to cite this article:}

Uma Sankar Gorla et. al., In vitro alpha amylase inhibitory activity of crude ethanol extract of terminalia chebula leaves. Int. J. Adv. Pharm. Biotech., 2016; 2(2): 1-5. 